\title{
Sensible or Outdated? Gender and Opinions of Tenure Criteria in Canada
}

Jennifer Dengate

University of Manitoba

Annemieke Farenhorst

University of Manitoba

Tracey Peter

University of Manitoba

\begin{abstract}
The university reward structure has traditionally placed greater value on individual research excellence for tenure and promotion, influencing faculty's allocation of time and definition of worthwhile labour. We find gender differences in Canadian natural sciences and engineering faculty's opinions of the traditional criteria for measuring academic success that are consistent with an implicit gender bias devaluing service and teamwork. Most women recommend significant changes to the traditional model and its foundation, while a substantial minority of men support the status quo. However, this comparative qualitative analysis finds more cross-gender similarities than differences, as most men also want a more modern definition of success, perceiving the traditional model to be disproportionately supportive of one type of narrow research scholarship that does not align with the realities of most faculty's efforts. Thus, this study suggests a discrepancy between traditional success criteria and faculty's understanding of worthwhile labour.
\end{abstract}

\section{Résumé}

Dans un paradigme plus traditionnel, l'évaluation du rendement en milieu universitaire a eu tendance à privilégier la recherche individuelle dans le cadre de la promotion et de l'octroi de la permanence. Cette tendance a eu pour effet 
d'influencer les chercheurs et les chercheuses dans leur emploi du temps et dans leur conception d'un travail valorisant. Nous signalons la présence de différences liées au genre dans les opinions du corps professoral en sciences pures et en ingénierie au Canada quant à l'évaluation du rendement qui sont cohérentes avec des préjugés sexistes qui dévalorisent le service à la collectivité et la collaboration. La majorité des femmes revendiquent des changements importants par rapport au paradigme dominant et aux modèles traditionnels, alors qu'une minorité significative des hommes défend le statu quo. Notre analyse comparative qualitative indique toutefois plus de similitudes que de différences entre les sexes : la plupart des hommes souhaitent également une définition actualisée du rendement, car le paradigme traditionnel a tendance à privilégier un seul type de recherche qui ne se fait pas le reflet des activités professionnelles du corps professoral. Cette étude présente donc un écart entre le rendement tel qu'il est défini de manière traditionnelle et les conceptions actuelles du travail dit valorisant au sein du corps professoral.

\section{Acknowledgements}

The authors are grateful to the two anonymous reviewers for their comments and suggestions; and would like to thank the Natural Sciences and Engineering Research Council Women in Sciences and Engineering Program for supporting this research.

\section{Introduction}

Institutional criteria for success are vital in achieving tenure and promotion, influencing university faculty's allocation of time and definition of worthwhile labour. In 2017, nearly $28 \%$ of all Canadian full professors were women, up from 20.3\% in 2007 (CAUT, 2018). However, women in natural sciences and engineering (NSE) were more likely to be assistant and associate professors than full professors (CAUT, 2018). In 2014, fewer than $20 \%$ of full professors in fields such as agriculture, computer science, and physical sciences were women. Moreover, it may take significantly longer for women to advance in NSE fields, relative to men (Ornstein, Stewart, \& Drakich, 2007). Together, this evidence suggests women in male-dominated NSE may be encountering stronger barriers to advancement, relative to more gender balanced fields (e.g., education) (CAUT, 2014). The persistence of gender gaps in rank at the university and discipline levels indicates a need to examine the extent to which faculty performance criteria are gendered.

The existing "traditional" model of faculty success assesses performance in research, teaching, and service. However, research is most valued (Bird, Litt, \& Wang, 2004). Individual achievements are also worth more than collective efforts (e.g., principal vs. coinvestigator) (e.g., Acker \& Armenti, 2004). As such, some have argued that a masculine bias is embedded within the university's structure, systematically devaluing teaching and, especially, service, for which women bear a disproportionate responsibility (Park, 1996). We investigate how the traditional model is viewed within gendered NSE departments: How do men and women define academic success and do they consider the existing crite- 
ria to be sufficiently inclusive?

Compared to the U.S., surveys of Canadian faculty experiences are few but increasing (e.g., Jones et al., 2012; Gopaul et al., 2016). There is also invaluable qualitative research detailing female education, social work, and science faculty's experiences (e.g., Acker \& Armenti, 2004). However, less is known about the particular experiences of NSE faculty, as existing studies tend to pool multiple disciplines. Accordingly, this research adds to the literature through a comparative qualitative analysis of Canadian NSE faculty's preferred approaches to scholarly evaluation.

\section{Literature Review}

According to the gendered organizations framework, a masculine bias is embedded within the structure of the academy. Such bias includes evaluation processes that promote male advantage, reproducing hierarchies of power wherein women are underrepresented in the more senior ranks (Acker, 1990; Bird, 2011). Although there is variation in universities' performance standards and review processes (Gravestock, 2011), tenure and promotion generally depend upon achievement in research, teaching, and service (Acker, Webber, \& Smyth, 2012). Research and teaching matter more than service (Bellas, 1999). This is consistent with a "40/40/20" split where faculty are expected to devote approximately $40 \%$ of their time to research, $40 \%$ to teaching, and $20 \%$ to service, though the exact division may vary. However, research achievement is most valued (Acker \& Webber, 2017; Park, 1996).

Prioritizing research affects all faculty but may be especially relevant for those in NSE. The traditional sciences are "high consensus fields", characterized by a relatively stronger research orientation, more time spent on research, greater funding, and higher publication rates (Ornstein et al., 2007, p. 4). As such, NSE departments may emphasize research success (e.g., number of publications per year) more than the humanities, for example.

\section{Tenure and Promotion in Canada}

Tenure reviews in Canada are rigorous and lengthy but generally have high success rates. Moreover, men and women receive tenure at comparable rates but gender (and other) differences can be overshadowed by this apparent equality (Acker et al., 2012). Men are more likely to be promoted and advance more quickly, for instance. On average, men are promoted from assistant to associate professor about 5 months earlier; and from associate to full professor about one year sooner than women (Stewart, Ornstein, \& Drakich, 2009).

Ornstein and colleagues (2007) found discipline variation mediated gender differences with women being promoted faster in fields where they were better represented, such as education. Engineering, science, math, and computer science had the shortest median times for promotion to associate professor but women in these fields still experienced delays. Controlling for discipline and institution type, women reached the rank of full professor about one year later than men but the gender discrepancy was greatest in science and engineering. Nevertheless, institutional variation outweighed both gender and discipline differences with large, science-oriented institutions having shorter promotion times, overall (Ornstein et al., 2007, p. 19). 
Those overseeing tenure review may not be cognizant of how "objective" processes can affect people differently. Acker and colleagues (2012) concluded that faculty deviating from "the mainstream"-including immigrants, those for whom English is a second language, and women-may have more trouble with the tenure process (p. 751). These unrecognized biases are relevant because the legitimacy of evaluation criteria (and, thus, the gendered hierarchies they reproduce) depends on the belief they reflect an unbiased organizational logic, appropriately rewarding different levels of skill (Acker, 1990). On the contrary, a significant body of literature has demonstrated that academic success assumes an ideal masculine worker who can privilege career, especially above caregiving (e.g., working evenings/weekends) (Barrett \& Barrett, 2011; Mason \& Goulden, 2004; Williams, 2004). Moreover, it is argued that the hierarchical scholarly reward structure rests upon a gendered division of labour where women are assigned the greatest responsibility for the least valued tasks (Bellas, 1999; Bird et al., 2004; Park, 1996).

\section{Gendered Academic Workloads}

Some American studies using multi-disciplinary faculty samples, including NSE, have found that men spend significantly more time engaged in research, while women do more service (Guarino \& Borden, 2016; Link, Swann, \& Bozeman, 2008; Misra, Lundquist, Holmes, \& Agiomavritis, 2011). However, the evidence describing American NSE faculty workloads is mixed: Jackson (2004) found no gender difference in research productivity amongst white engineering faculty, but white women reported more external service than white men; and there is also some evidence of male NSE faculty performing significantly more service than women, for example (Carrigan, Quinn, \& Riskin, 2011).

Female faculty in Canada, the U.K., and the U.S. may be disproportionately responsible for students' emotional needs as well (Acker \& Feuerverger, 1996; Barrett \& Barrett, 2011; Statham, Richardson, \& Cook, 1991). Many women value this work but the gender gap does not simply reflect differences in preference. Assumed to be more compassionate, American female faculty may face more pressure to perform devalued service and caring labour (Barnes-Powell \& Letherby, 1998; Pyke, 2011). Moreover, Canadian women are more likely to occupy the junior ranks, which may coincide with heavier teaching/student loads (CAUT, 2018; Park, 1996). Similarly, Barrett and Barrett (2011) note that part-time or contract positions can limit female U.K. scholars to teaching, which may contribute to reduced advancement prospects. Accordingly, women appear to encounter more cultural and structural constraints on their time, detracting from research (e.g., Winslow, 2010), impeding their efforts to meet traditional success criteria.

The reward hierarchy underlying the traditional model best positions those who focus on research for tenure and promotion. Insofar as this is the case, the traditional definition of success is not inclusive or objective; disadvantaging women and marginalizing faculty who must spend a lot of time on other activities. Indeed, there is evidence suggesting Canadian faculty are somewhat divided over the role of research (e.g., Gopaul et al., 2016).

\section{Canadian Faculty and the Traditional Success Model}

Existing evidence suggests many Canadian faculty prioritize research, consistent with assertions that the traditional model is biased. The Changing Academic Profession (CAP) 
survey found more than $75 \%$ of full-time tenured and tenure-track Canadian faculty (from a variety of disciplines, including NSE) valued both research and teaching (Gopaul et al., 2016). However, the majority leaned more toward research than teaching (54\% vs. $26 \%$, respectively). In addition, $75 \%$ of Canadian faculty felt "scholarship is best defined as the preparation and presentation of findings on original research" (Gopaul et al., 2016). Yet, in her review of Canadian tenure policies, Gravestock (2011) found no explicit preference for research over teaching. Instead, she concluded commonly held perceptions of institutional research preference may stem from the misinterpretation or misapplication of assessment policies (pp. 262-263).

At the same time, the CAP survey revealed that $72 \%$ of Canadian faculty agreed "high expectations to increase research productivity are a threat to research quality" (Gopaul et al., 2016, p. 64). While Gopaul and colleagues (2016) concluded these results indicated apprehension about societal issues dictating research, the findings also suggest institutional and faculty priorities have diverged. Indeed, interviews with pre-tenure Canadian assistant professors in sociology, political science, geography, and education found early career academics were critical of performance review criteria/processes, with some singling out reliance on "measured outputs" (e.g., publications in top-ranked journals) (Acker \& Webber, 2017, p. 546).

Further, rising standards and emphasizing grants and publications have contributed to some Canadian women academics' anxiety about tenure review and difficulty meeting promotion criteria, respectively (Acker \& Armenti, 2004; Acker \& Webber, 2017). In addition, Acker and Feuerverger (1996) found female education professors were dismayed that their disproportionate service and student/colleague care efforts were undervalued.

Overall, these findings suggest a partial mismatch between institutional and Canadian faculty values, enough to beg the question as to how much support there is for the traditional model and whether support varies by gender. This question is especially relevant for NSE faculty as these departments continue to be dominated by men, with women likely holding junior positions and, perhaps, also performing significantly more service (CAUT, 2018; Misra et al., 2011). We expect men, who may already disproportionately benefit from the status quo, will be more resistant to change. In contrast, women are expected to favour significant transformation in order to see devalued service and caregiving labour better represented (Acker \& Feuerverger, 1996).

\section{Methodology}

We administered a cross-sectional workplace experiences survey to NSE faculty from five Canadian universities, including medical/doctoral and comprehensive institutions. The sampling frame was constructed from university websites and 1,883 NSE faculty received an email invitation with a link to access the survey online. A total of 421 surveys were completed, representing a response rate of $22 \%$. The survey covered a number of topics expected to influence workplace climate, including work-life balance and harassment and discrimination.

The sample is $65.4 \%$ male and $34.6 \%$ female, largely made up of full professors (49.7\%). Associate and assistant professors comprise $25.9 \%$ and $16.8 \%$ of the total, respectively, and the remaining $7.6 \%$ are teaching stream faculty. Just over three-quarters of the sample is tenured (75.9\%), while $15.4 \%$ have a probationary appointment or continuing 
appointment (8.6\%). The mean age is 50 years old. The vast majority are white (86.1\%) and identify as heterosexual (94.2\%). Most respondents work in science-related units (54.8\%), followed by engineering (20.9\%), agriculture (18.8\%), and other fields (5.5\%), such as environmental sciences. This analysis is based on responses to an open-ended question asking how universities could recognize multiple models of faculty success. We compiled a total of 131 written comments for analysis: 74 from men, 47 from women, and 10 from faculty whose gender could not be determined due to non-response. Accordingly, $31 \%$ of the total survey sample responded to the question analyzed in this paper.

We took the constant comparison approach, including multiple rounds of open and focused coding (Corbin \& Strauss, 1990; 2008). Men's and women's statements were coded separately and comparisons were made within and between the gender categories. Statements (not individuals) were assigned a "preferred model of success" code according to whether, and in what way, their suggestions deviated from the traditional model (e.g., type and magnitude of difference) (Lofland, Snow, \& Lofland, 2006). Concurrent conceptual memos helped elaborate faculty definitions of success (Corbin \& Strauss, 1990; 2008). The advantage of applying inductive techniques is the ability to generate highly valid concepts and associations directly from faculty's own experiences. However, the nature of our data did not permit a complete grounded theory analysis. Specifically, survey data does not allow probing questions or the saturation of conceptual and theoretical categories to the same degree as interviews or a purposive sampling approach (Corbin \& Strauss, 1990; 2008). Nevertheless, the constant comparative method still enabled a thorough analysis of gender differences.

Four success models were identified: conservative/traditional, modern, progressive, and replacement. The conservative/traditional model considers the existing criteria to be inclusive enough. The modern model weighs academic activities more equally and flexibly and, as a result, includes a wider range of pursuits. The progressive model aims to re-orient the underlying value system, shifting from individual achievements to team contributions, for example. Finally, the replacement model seeks to eliminate tenure and install a different system.

Individual statements could be consistent with more than one model:

There should be a pathway other than substantially just research to obtain tenure - i.e., the current balance is such that teaching plays a minor role in obtaining tenure. I do not believe tenure really serves the real purpose for which it was originally intended and perhaps should be abolished altogether. (male)

This quotation aligns with the modern and replacement models. De-emphasizing research and the implied need to increase the value of teaching reflects a modernized definition of success, whereas "abolishing" tenure requires a new system be put in place.

Because of the potential for multiple model support within a single answer, the total number of statements corresponding with each model were added up for both men and women. A greater number of statements indicates greater preference for a model. Regardless of the number of statements a single faculty member made in support of a particular model, only one code was assigned: If 3 statements in support of the progressive model were made within the same block of text only 1 code was added to the progressive model's total. Additional statements were used to refine the model's dimensions and underlying 
rationale (Lofland et al., 2006).

Once the most and least "favoured" models were identified for men and women, they were compared against one another to identify additional similarities or differences (e.g., comparing the "progressive women" to the "replacement men", since these models call for the greatest change to the traditional model). The statements from those unable to be categorized as male or female were used as a final point of comparison and did not indicate the need for any additional model types.

\section{Results}

We find gender differences in the results, with men being more likely to support the conservative/traditional model of success than women (see Table 1), consistent with assertions of masculine bias in the existing academic reward structure (e.g., Park, 1996). However, there are also clear gender similarities, with most men and women favouring the modern model, suggesting the traditional model may be increasingly unrealistic or undesirable for many men as well.

Table 1. Preferred Model of Faculty Success by Gender

\begin{tabular}{lcc}
\hline \multicolumn{1}{c}{ Success Model } & Men's Statements & Women's Statements \\
\cline { 2 - 3 } Modern & 36 & 27 \\
Conservative/Traditional & 20 & 3 \\
Progressive & 5 & 14 \\
Replacement & 4 & 0 \\
\hline Total: & 65 & 44
\end{tabular}

We do not advocate for the superiority of any one model. The purpose of this research is to critically examine the gender distribution of Canadian NSE faculty's opinions of scholarly evaluation. Nevertheless, as we (the authors) are all women whose scholarly and/or advocacy work has often prioritized the structural obstacles women face in gendered contexts, including academic NSE, we are predisposed to emphasize gender difference from the perspective of women. As such, we endeavoured to identify and elaborate similarities between male and female faculty as much as differences, where appropriate.

\section{Conservative/Traditional Model}

This model maintains that the tradition of excellence in research, teaching, and service is sufficiently inclusive and many cite teaching streams, where present, as evidence. As one male professor notes, "We have teaching-only positions. That's a good thing. Other than that, I consider [multiple models of success] to be highly ill-advised". Some even assert the existing criteria are too lenient, ill-defined, and inconsistently applied because "nearly everyone gets tenure, including many who should not. [...] It is too much of a rubber stamp".

Overall, conservative/traditional statements conclude that the existing standard "works great," closely matching faculty's understanding of what it means (and what it takes) to be a tenured scholar: 
I think that the classical measures of success are all that is needed. Being a university professor is not a "make work" project for marginally intelligent people. It is about clearly demonstrating excellence in hard results-oriented research with clear measures on productivity and the same for teaching. (male)

Similarly, one female professor "discourage[s] a model that is too inward looking", advising continued emphasis on research, teaching, and service. Nevertheless, conservative/ traditional support does vary by gender. Consistent with our expectations, a substantial minority of men's statements promote the status quo, making it their second most favoured approach, while it is the second least supported amongst female faculty.

However, several men assert particular kinds of research are more highly valued and rewarded, creating an additional hierarchy amongst scholars. They state research that is consistent with the university's priorities and that which is supported by prestigious federal grants from the Natural Sciences and Engineering Research Council (NSERC), the Canadian Institutes of Health Research (CIHR), or the Social Science and Humanities Research Council (SSHRC) is privileged (see also Acker \& Webber, 2017):

I work in [field A], and there is a very definite bias in our department and Faculty towards [field B...]. Those colleagues who engage in [field B] research, receive much extra and ultimately unfair support from our Dean's Office and the central admin. (male)

The most striking difference amongst faculty of the same gender is between the men in support of the status quo and those favouring the modern model. However, the "modern men" are in the majority, as both genders appear to prefer an updated definition of success.

\section{Modern Model}

The modern model asserts the emphasis on research, teaching, and service is fundamentally appropriate but too restrictive and improperly measured and weighted. Therefore, tenure and promotion criteria should be expanded, made more flexible, and equalized to better capture the realities of academic work (e.g., unsuccessful grant applications):

My Faculty's tenure and promotion requirements are very rigid and need to be relaxed [...]. Because we are all measured against the same mythical standard, anyone who deviates from the model (research superstar, adequate teacher, does some service) is not rewarded for making more effort on the teaching or service categories. (male)

Many are dissatisfied with summary indicators of performance (Acker \& Webber, 2017):

[Get rid of student course evaluation] surveys entirely. They are misused by administrators who just want to generate a quick number and say "you're a good teacher" or "you're a bad teacher". [...] Research: Get off this obsession with breaking down "performance" into single 1-year windows. If you have 5 publications 1 year you are good. If the next year you have none, suddenly you're unsatisfactory. The university is so fixated on performance indicators that they don't bother to try 
to even grasp what it is that people are doing. (male)

Men and women agree that it is necessary to elevate three types of activities: 1) Interdisciplinary and collaborative work (including co-investigator roles); 2) A broader range of internal and external service activities, including "non-traditional" examples (e.g., advocacy, mentoring, undergraduate training, and student service); and 3) Innovation and entrepreneurial efforts (including patents):

Inclusion of innovation and entrepreneurship components - inclusions of attempts at grants and grant proposals that were not successful (as these require time and indicate effort) - ways to recognize [co-principal investigators] as indications of involvement in grants rather than just one PI [principal investigator]. (female)

Singling out entrepreneurial efforts is understandable for NSE faculty, given the rise of neo-liberal academic capitalism, namely, increasing institutional pressure for Canadian faculty to partner with the private sector and generate commercial revenue (Metcalfe, 2010). Similarly, another female professor wants the university to appreciate "ALL the work we do and not just what they have decided on" (original emphasis). Science promotion and communication is something she "take[s] seriously but [does] not get rewarded for". Thus, it is apparent that some NSE faculty feel current performance measures are somewhat invalid.

Some also express dissatisfaction with the emphasis on research, though they still confirm its central role in scholarship. Many of these particular faculty candidly acknowledge that "the message....is still highly focused on research output". Contrary to this, faculty strongly advocate for the university to "actually weigh teaching quality and research quality equally, rather than say that they have equal weight, but then ignore weak teaching when research is strong and ignore strong teaching when research is of average quality" (see also Osakwe, Keavey, Uzoka, Fedoruk, \& Osuji, 2015).

In addition, both genders confirm the devaluation of service. Many consider this unfair since it is essential to universities' success (Bird et al., 2004; Pyke, 2011). As one male faculty member states, "[the university] should acknowledge service to the discipline which, of course, has far more value than random committees of little import". Developing a service stream and greater recognition of external service efforts are suggestions made by faculty of both genders. Nevertheless, consistent with their disproportionate responsibility for this labour, women are more likely to call for increased value for external service. This is not too surprising, as half of the total survey sample is made up of full professors and senior female faculty in the U.S. have been found to engage in significantly more external service (Guarino \& Borden, 2016). Moreover, NSE women may be asked to help recruit more girls to these fields by acting as role models for various outreach initiatives (e.g., Stout, Dasgupta, Hunsinger, \& McManus, 2011; Weber, 2011).

Men are slightly more likely to want increased value for teaching. Some would like it to carry greater weight in tenure decisions; call for more teaching stream options, want teaching stream faculty to receive tenure, and for the university to publicly celebrate teaching efforts. Men's inclination to elevate teaching might be related to genuine respect for the activity or, perhaps, its already greater institutional value (compared to service) (e.g., Gopaul et al., 2016). Indeed, O'Meara (2016) found that some male faculty in the U.S. 
took a strategic approach, avoiding service unless it benefitted their careers. Women, in contrast, were more likely to consider service a collective responsibility (O’Meara, 2016). It is also possible that men could see a reduction in their teaching responsibilities, as new teaching stream positions may be more likely to be filled by women, given their continued overrepresentation in part-time and lower-rank full-time faculty positions (CAUT, 2018). In the latter case, more of men's collective time could be channeled into research.

The criticism of prioritizing research reflects the need for deeper structural change. If teaching and service are already subordinated, how likely is it that any other scholarly pursuits will be institutionally legitimated? The progressive model of success recognizes the need to target the gendered values underlying the reward system to effect changes in how faculty performance is conceived and judged (Bird et al., 2004; Park, 1996).

\section{Progressive Model}

The progressive model is the second-most favoured amongst female faculty. It prioritizes compensating skills, encouraging individuals to focus on their strengths. As one female professor states, "It is unrealistic for all faculty to excel at everything. A model that acknowledged strengths and commends strengths in employees would be more realistic and supportive".

Teamwork is central to this model which, as one female professor notes, contradicts the current "heavy emphasis on individual accomplishments, preferably easily represented by numbers". She adds, "There is little recognition for team building and support provided to others [...]. Yet, such efforts ensure that the entire department can succeed". Another woman agrees, further explaining, "We are not all exceptional at all things or at the same things. We need to recognize and reward diversity and appreciate the contributions that everyone makes". Thus, this vision is analogous to the concept of organic solidarity where advanced societies characterized by a complex division of labour are necessarily interdependent (Durkheim, 1933, 1997). In focusing on departments' collective success, devalued labour may be elevated (e.g., service).

Performance evaluation requires the negotiation of customized faculty targets:

The 40/40/20 split is tough...maybe by asking for excellence in one area and good performance in the others? Or by assigning work in relation to what the focus of the faculty member might be that year AND [meeting or not meeting] the agreed upon goals [should] be the basis for merit/performance review. (female)

The emphasis on teamwork and interdependence may lead some to argue the progressive model would unfairly favour women, reflecting gendered cultural beliefs about women's and men's "natures" and inherent competencies within a particular work setting (e.g., Ridgeway \& Correll, 2004). The faculty data challenge this assertion as men also support the progressive model. One man notes the limitations of privileging individual achievements stating, "Teamwork and team-building is not recognized sufficiently. The [current] system encourages individual scholars who will have difficulty competing with far better funded groups in other countries". Some men are also open to customized evaluation criteria and specialized career tracks concluding, "if [the question] is to suggest that different units may benefit from different models, then the answer is yes"; and that "it would 
be good to see a distinction, even within individual [research and teaching] streams".

In contrast, the criticism that the traditional success model has an implicit male bias is not based on essentialist cultural stereotypes of masculinity (e.g., men are more rational and, thus, they have greater success in scientific research) (England, 2010). The traditional model is argued to contain a "masculine" bias because, overall, men appear better positioned to focus on research (e.g., Misra et al., 2011). As a group, female faculty are disadvantaged by their disproportionate responsibility for devalued service and student care work, which demands more of their time and attention (Acker \& Feuerverger, 1996; Bird et al., 2004). Therefore, the criticism is primarily intended to highlight structural obstacles differentially affecting women, which are informed by stereotypes of femininity (e.g., women are more compassionate and nurturing). The progressive model counterbalances this underlying bias, enabling more women and men, who presently feel marginalized by research preference, to be equally rewarded for service and other supportive efforts. The progressive model changes are significant but strategic. Some men also feel it is imperative to fundamentally transform tenure but through abrupt procedural change.

\section{Replacement Model}

The replacement model is only supported by men. However, these statements constitute a very small minority of the total (just 4 comments in all). Statements advocating for the replacement model assert that the existing tenure system should be replaced with 5 -year renewable contracts, a point system for awarding promotion, or the requirement for faculty to be nominated by their superiors.

The replacement and progressive models are similar in that they demand significant transformation of the existing evaluation system. However, the progressive approach is more likely to produce inclusive success criteria because it is rooted in the understanding that unless the underlying gendered reward structure is changed, women (and others deviating from the traditional model) will remain disadvantaged. The replacement model substitutes one process with another, which does not address the underlying structure. Without correcting biases in evaluating work and performances (e.g., individual research outputs valued over collaboration and service), one particular type of scholar can still systematically receive more points, be nominated, and have their contracts renewed more often and more quickly. This may be especially true in male-coded NSE fields where women may be considered less competent to begin with (Moss-Racusin et al., 2012).

\section{Discussion}

The persistence of the traditional success model rests on the belief that its standards are objective, equally achievable by all (Acker, 1990). On the contrary, our analysis demonstrates that many faculty members perceive bias in this model and want change. However, consistent with the assertion that the university's structure privileges men (Bird et al., 2004; Park, 1996), female NSE faculty are more likely to advocate for significant change than their male colleagues.

Women are more likely to support modern and progressive models of success which are complementary, if not interdependent, as they redefine faculty performance through an appreciation of varied strengths and skills. Without progressive structural changes, 
isolated modern changes to the tenure review process "on paper" (e.g., requiring equal weight be given to research, teaching, and service efforts) are unlikely to be consistently implemented or internalized by faculty in practice (i.e., the culture remains the same). Extra teaching may still be devalued, compared to research, unless and until it is sufficiently "celebrated and appreciated publicly" by the administration, perhaps through teaching awards or grants (e.g., Gravestock, 2011).

In contrast, men are more likely to support the modern and conservative models. The rift between support for the status quo and change is important, as it indicates the existing model and its apparent preference for certain types of research output may be becoming increasingly restrictive and unfavourable to NSE men and women. Such results contradict existing evidence indicating Canadian faculty generally felt they retained research autonomy, despite the influence of external funding agencies (Gopaul et al., 2016). As such, our findings suggest a discrepancy amongst institutional performance criteria and NSE faculty's experiences, workloads, and values which stresses the importance of investigating differences amongst academic units.

\section{Policy Implications and Future Research}

It is beyond the scope of this paper to offer recommendations on how to implement a new model. Universities are complicated bureaucracies with multiple hierarchies of power, contradictory messages, and practices that vary between departments, faculties, and central administration (Bird, 2011). Indeed, some of the complexities are highlighted in these data, as multiple faculty members maintain their institution's definition of success is already inclusive to the extent that "department chairs choose to promote [inclusivity] for their units". In addition, most Canadian faculty belong to unions (Acker et al., 2012; Jones et al., 2012); and tenure criteria are outlined in collective agreements (Acker \& Webber, 2017). As such, any revision to tenure and promotion procedures would need to involve faculty associations.

Nevertheless, it is evident from these results that a re-examination of performance criteria may be necessary if they are to remain relevant to faculty, in general (e.g., Osakwe et al., 2015), and NSE faculty, in particular. Perceived gender bias in performance assessment might compound existing masculine biases in NSE cultures, such as men's greater feelings of unit inclusion and access to equipment (Fox, 2010), constituting an additional impediment to the retention of women (e.g., Powell et al., 2004). As illustrated by the specific call to acknowledge "science communication and promotion" in these data, female NSE faculty may grow increasingly dissatisfied if they feel they are not being evaluated for the "right things" (i.e., tasks they feel best illustrate their accomplishments or unique contributions) (Powell et al., 2004). Moreover, as one anonymous reviewer noted, failure to review or update performance criteria could lead NSE scholars (of any gender) to leave the academy for private industry or civil service, given the applicability of their skills and knowledge across employment sectors. However, our results cannot be generalized beyond this particular sample of NSE faculty and, as such, a faculty survey administered to a representative sample of Canadian scholars from multiple disciplines would be beneficial. Specifically, a focused survey can measure support for the traditional model, academics' ideal/preferred criteria, and the potential consequences of failing to update existing criteria (e.g., intent to leave the university or stress). 
In addition, our data did not permit an examination of age-related differences or the interaction between age and gender. It is possible that older faculty members may prefer the existing conservative/traditional success model, while younger faculty of both genders may lean more towards modernizing definitions of success (e.g., White, 2015). Likewise, we were unable to examine differences related to racialized background and sexual minority status, given the very small number of respondents claiming these identities. Future studies may be better able to examine both generational and intersectional variation to identify the nuances of structural academic bias, informing the development of appropriately inclusive employment practices (Acker et al., 2012).

\section{Conclusion}

Despite officially including research, teaching, and service, the traditional model of faculty success privileges research. Consequently, the persistence of this model may perpetuate an asymmetric reward hierarchy, systematically disadvantaging women who bear a disproportionate responsibility for service (Park, 1996); and those that otherwise deviate from a narrow, idealized definition of scholarly excellence, male or female (e.g., Acker et al., 2012). Understanding and repairing this disconnection is relevant to increasing workplace equality within Canadian academia.

\section{References}

Acker, J. (1990). Hierarchies, jobs, bodies: A theory of gendered organizations. Gender \& Society, 4(2), 139-158. https://doi.org/10.1177/089124390004002002

Acker, S., \& Armenti, C. (2004). Sleepless in academia. Gender and Education, 16(1), 3-24. https://doi.org/10.1080/0954025032000170309

Acker, S., \& Feuerverger, G. (1996). Doing good and feeling bad: The work of women university teachers. Cambridge Journal of Education, 26(3), 401-421. https://doi. org/10.1080/0305764960260309

Acker, S., \& Webber, M. (2017). Made to measure: Early career academics in the Canadian university workplace. Higher Education Research \& Development, 36(3), 541554. https://doi.org/10.1080/07294360.2017.1288704

Acker, S., Webber, M., \& Smyth, E. (2012). Tenure troubles and equity matters in Canadian academe. British Journal of Sociology of Education, 33(5), 743-761. https:// doi.org/10.1080/01425692.2012.674784

Barnes-Powell, T., \& Letherby, G. (1998). "All in a day's work: Gendered care work in higher education. In D. Malina \& S. Maslin-Prothero (Eds.), Surviving the academy: Feminist perspectives (pp. 69-77). Philadelphia, PA: Falmer Press, Taylor \& Francis Inc.

Barrett, L., \& Barrett, P. (2011). Women and academic workloads: Career slow lane or cul-de sac? Higher Education, 61, 141-155. https://doi.org/10.1007/s10734-010-9329-3

Bellas, M. L. (1999). Emotional labor in academia: The case of professors. Annals of the Academy of Political and Social Science, 561, 96-110.

Bird, S. R. (2011). Unsettling universities' incongruous, gendered bureaucratic structures: A case-study approach. Gender, Work and Organization, 18(2), 202-230. https://doi.org/10.1111/j.1468-0432.2009.00510.x 
Bird, S., Litt, J., \& Wang, Y. (2004). Creating status of women reports: Institutional housekeeping as "women's work". NWSA Journal, 16(1), 194-206. https://www.jstor. org/stable/4317042

Canadian Association of University Teachers. (2014). CAUT almanac of postsecondary education in Canada 2013-2014. Ottawa, ON: Canadian Association of University Teachers.

Canadian Association of University Teachers. (April, 2018). Underrepresented \& underpaid: Diversity \& equity among Canada's post-secondary teachers. Retrieved from https://www.caut.ca/sites/default/files/caut_equity_report_2018-04final.pdf

Carrigan, C., Quinn, K., \& Riskin, E. A. (2011). The gendered division of labor among STEM faculty and the effects of critical mass. Journal of Diversity in Higher Education, 4(3), 131-146.

Corbin, J., \& Strauss, A. (1990). Grounded theory research: Procedures, canons and evaluative criteria. Zeitschrift für Soziologie, 19(6), 418-427.

Corbin, J., \& Strauss, A. (2008). Basics of qualitative research: Third edition. Thousand Oaks, CA: Sage.

Durkheim, E. (1933/1997). The division of labor in society. New York City, NY: The Free Press.

England, P. (2010). The gender revolution: Uneven and stalled. Gender \& Society, 24, 149-166. https://doi.org/10.1177/0891243210361475

Fox, M. F. (2010). Women and men faculty in academic science and engineering: Social organizational indicators and implications. American Behavioral Scientist, 53(7), 997-1012. https://doi.org/10.1177/0002764209356234

Gopaul, B., Jones, G. A., Weinrib, J., Metcalfe, A., Fisher, D., Gingras, Y., \& Rubenson, K. (2016). The academic profession in Canada: Perceptions of Canadian university faculty about research and teaching. Canadian Journal of Higher Education, 46(2), 55-77.

Gravestock, P.S. (2011). Does teaching matter? The role of teaching evaluation in tenure policies at selected Canadian universities (Doctoral dissertation). Retrieved from https:// tspace.library.utoronto.ca/bitstream/1807/31764/6/Gravestock_Pamela_S_201111_ PhD_thesis.pdf

Guarino, C. M., \& Borden, V. M. H. (2016). Faculty service loads and gender: Are women taking care of the academic family? IZA Discussion Papers, no. 10010.

Jackson, J. (2004). The story is not in the numbers: Academic socialization and diversifying the faculty. NWSA Journal, 16(1), 172-185. https://www.jstor.org/ stable/4317040

Jones, G., Weinrib, J., Metcalfe, A. S., Fisher, D., Rubenson, K., \& Snee, I. (2012). Academic work in Canada: The perceptions of early-career academics. Higher Education Quarterly, 66(2), 189-206. https://doi.org/10.1111/j.1468-2273.2012.00515.x

Link, A., Swann, C., \& Bozeman, B. (2008). A time allocation study of university faculty. Economics of Education Review, 27(4), 363-374. https://doi.org/10.1016/j. econedurev.2007.04.002 
Lofland, J., Snow, D., \& Lofland, L. H. (2006). Analyzing social settings: A guide to qualitative observation and analysis: Fourth edition. Toronto, ON: Nelson.

Mason, M. A., \& Goulden, M. (2004). Marriage and baby blues: Redefining gender equity in the academy. Annals of the Academy of Political and Social Science, 596, 86103. http://journals.sagepub.com/doi/abs/10.1177/oo02716204268744

Metcalfe, A. S. (2010). Revisiting academic capitalism in Canada: No longer the exception. The Journal of Higher Education, 81(4), 489-514. https://doi.org/10.1080/o 0221546.2010.11779062

Misra, J., Lundquist, J. H., Holmes, E., \& Agiomavritis, S. (2011). The ivory ceiling of service work. Academe, 97(1), 22-26.

Moss-Racusin, C. A., Dovidio, J. F., Brescoll, V. L., Graham, M. J., \& Handelsman, J. (2012). Science faculty's subtle gender biases favor male students. Proceedings of the National Academy of Sciences, 109(41), 16474-16479. https://doi.org/10.1073/ pnas.1211286109

O'Meara, K. (2016). Whose problem is it? Gender differences in faculty thinking about campus service. Teachers College Record, 118(080306), 1-38.

Ornstein, M., Stewart, P., \& Drakich, J. (2007). Promotion at Canadian universities: The intersection of gender, discipline, and institution. Canadian Journal of Higher Education, 37(3), 1-25.

Osakwe, C., Keavey, K., Uzoka, F. M., Fedoruk, A., \& Osuji, J. (2015). The relative importance of academic activities: Autonomous values from the Canadian professoriate. Canadian Journal of Higher Education, 45(2), 1-22.

Park, S. M. (1996). Research, teaching, and service: Why shouldn't women's work count? The Journal of Higher Education, 67(1), 46-84. https://doi.org/10.1080/002215 46.1996.11780249

Powell, A., Bagilhole, B., Dainty, A., \& Neale, R. (2004). Does the engineering culture in UK higher education advance women's careers? Equal Opportunities International, 23(7/8), 21-38. https://doi.org/10.1108/02610150410787882

Pyke, K. (2011). Service and gender inequity among faculty. Political Science \& Politics, 44(1), 85-87. https://doi.org/10.1017/S1049096510001927

Ridgeway, C. L., \& Correll, S. J. (2004). Unpacking the gender system: A theoretical perspective on gender beliefs and social relations. Gender \& Society, 18(4), 510-531. https://doi.org/10.1177/0891243204265269

Statham, A., Richardson, L., \& Cook, J. A. (1991). Gender and university teaching: A negotiated difference. Albany: State University of New York Press.

Stout, J. G., Dasgupta, N., Hunsinger, M., \& McManus, M. A. (2011). STEMing the tide: Using ingroup experts to inoculate women's self-concept in science, technology, engineering, and mathematics (STEM). Journal of Personality and Social Psychology, 100 (2), 255-270. https://doi.org/10.1037/a0021385

Stewart, P., Ornstein, M., \& Drakich, J. (2009). Gender and promotion at Canadian universities. Canadian Review of Sociology, 46(1), 59-85. https://doi.org/10.1111/j.1755- 
618X.2009.01203.X

Weber, K. (2011). Role models and informal STEM-related activities positively impact female interest in STEM. Technology and Engineering Teacher, (November), 18-21.

White, K. (2015). Are we serious about keeping women in science? The Australian Universities' Review, 57(2), 84-86.

Williams, J. C. (2004). Hitting the maternal wall - Before they reach a "glass ceiling" in their careers, women faculty may hit a maternal wall. Academe Bulletin of the American Association of University Professors, 90, 16-20.

Winslow, S. (2010). Gender inequality and time allocations among academic faculty. Gender \& Society, 24(6), 769-793. https://doi.org/10.1177/0891243210386728

\section{Contact Information}

Jennifer Dengate

University of Manitoba

Jennifer.Dengate@umanitoba.ca

Dr. Jennifer Dengate received her doctorate in sociology from the University of British Columbia in 2017 and is presently a postdoctoral fellow at the University of Manitoba. She is trained in both qualitative and survey methods; and her research emphasizes the intersection of job context and workplace/government policies on women's employment experiences, including the integration of work and family (e.g., maternity and parental leave). She is currently committed to investigating women's experiences in academic and private sector science, engineering, trades, and technology (SETT) contexts to support the retention of female employees.

Dr. Annemieke Farenhorst is a Professor of Soil Science at the University of Manitoba. She is the Prairie NSERC Chair for Women in Science and Engineering and the director of the NSERC CREATE H2O program for First Nations water and sanitation security. Dr. Farenhorst conducts research on pesticides, natural steroid estrogens and antibiotics in soil and water. She is the Canadian representative on the Division VI Chemistry and the Environment Committee of the International Union of Pure and Applied Chemistry, and an associate editor for the Journal of Environmental Science and Health, Part B: Pesticides, Food Contaminants, and Agricultural Wastes.

Dr. Tracey Peter is a Professor of Sociology at the University of Manitoba. She has been involved in numerous large-scale national studies involving youth and other marginalized populations. Her general research and publication interests include: research methods/applied statistics, mental health and well-being, education and work, and issues of homophobia and transphobia. 